\section{DiscoverSys \\ Published by DiscoverSys \\ Achieving ideal mentoring: working patterns among clinical instructors, nurses, and nursing students}

\author{
Ayu Sugiantari, ${ }^{1 *}$ Komang Ayu Kartika Sari, ${ }^{2}$ Pande Putu Januraga ${ }^{2}$
}

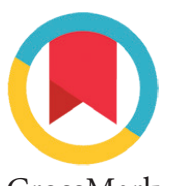

CrossMark

\section{ABSTRACT}

Background and purpose: The relationships between those responsible for clinical training, clinical instructors ( $\mathrm{Cls}$ ) and nurses, and the nursing students, have a great impact upon student learning during clinical placements. The present study investigates the pattern of working relationships among $\mathrm{Cls}$, nurses, and student nurses, and analyses the extent to which they achieve ideal mentoring practices. Methods: Qualitative study employing in-depth interviews with Cls $(n=3)$, nurses $(n=8)$, and nursing students $(n=8)$ on a clinical placement was undertaken from June-July, 2017, at Badung District Hospital, Denpasar, Bali. Content analysis was conducted to identify the key themes that emerged from these interviews and formed the basis of the findings. The results are presented narratively in order to highlight the patterns of the working relationships identified and perceived by $\mathrm{Cls}$, nurses, and nursing students, with the aim of developing improved mentoring practices.

Results: Analysis of the in-depth interviews identified three main themes: (i) perceptions on the hospital's mentoring practices, (ii) the role(s) and behaviour in the mentoring process, and (iii) the patterns of working relationships between those involved in the mentoring process. In general, participants defined mentoring in terms of the provision of guidance and instruction to students. Participant's contrasting perceptions of their role(s) affected how they behaved in the mentoring process. Furthermore, participant's perceptions of their own's roles and their behaviour provides a detailed overview of the working relationships pattern of the nursing students, nurses and Cls. Specifically, working relationships between Cls and nurses tend to fit an employee-employer type pattern, whereas those between Cls/nurses and nursing students do not appear to reflect typical mentor-mentee relationships.

Conclusions: The pattern of working relationships identified between Cls/nurses and nursing students do not, in fact, reflect a typical mentor-mentee relationship. Furthermore, this paper highlights the impact that suboptimal mentoring may have on nursing students' achievement of medical competence, as well as on the quality of nursing care provided to patients in teaching hospitals.
'Badung District Hospital, ${ }^{2}$ Department of Public Health and Preventive Medicine, Faculty of Medicine, Udayana University
*Correspondence to: Ayu Sugiantari, Badung District Hospital, ayusugiantari83@gmail.com

Keywords: perception, behaviour, pattern of working relationship, mentoring

Cite This Article: Sugiantari, A., Sari, K.A.K., Januraga, P.P. 2018. Achieving ideal mentoring: working patterns among clinical instructors, nurses, and nursing students. Public Health and Preventive Medicine Archive 6(1): 48-54. D0I:10.15562/phpma.v6i1.9

\section{INTRODUCTION}

Teaching hospitals have dual functions; they represent centres of education and research as well as providing healthcare to patients in an integrated manner. ${ }^{1}$ In order to carry out these roles successfully, teaching hospitals should be able to provide appropriate health care services according to patient's medical needs; uphold high standards of patient care and safety, and facilitate effective educational programs including nursing training.

During training, nursing students have neither the competence nor authority to perform nursing-care tasks independently; they must be supervised and guided by CIs or nurses at all times. ${ }^{2}$ Effective guidance should both increase student's competency inline with their clinical learning objectives and prevent errors during the execution of medical tasks such as the dilution of medication; incorrect dosing; or any other issues which may cause harm either to the patients or indeed, the students themselves, in terms of possible legal consequences resulting from negligence or mistakes. ${ }^{3-5}$
Thus, to prevent such issues, students are required to be supervised at all times while on medial placement. ${ }^{6}$ Furthermore, effective learning requires a conducive learning environment that fosters effective interpersonal relationships between CIs, nursing staff, and their students. ${ }^{7}$ The importance of effective mentoring and the creation of a conducive learning environment for student nurses are often overlooked by educational providers and teaching hospitals, and even by CIs themselves, due to a lack of awareness about nursing student's needs and the issues they may face. Furthermore, staff nurses often tend to wrongly assume that nursing students know the correct procedure to follow in any given medical situation. ${ }^{8}$ As a result, nursing students on clinical placements tend to spend most of their time performing routine tasks which often involve tough manual work. ${ }^{9}$ There tends to be a lack of delegation of nursing tasks appropriate to student's level of ability or scope of clinical practice. ${ }^{9}$ 
Therefore, clinical mentoring and the creation of a conducive learning environment for clinical practice can be improved by investigating and gaining a more in-depth understanding of the patterns of working relationships among teaching staff (CIs and nurses) and nursing students involved in clinical placements. With this in mind, the present paper presents a detailed qualitative analysis of patterns of interactions among CIs, nurses, and nursing students in terms of achieving ideal clinical-placement mentoring at Badung District Hospital, Denpasar, Bali.

Badung District Hospital is a satellite teaching hospital linked to Sanglah General Hospital, Denpasar, Bali, which is the main teaching hospital for the Medical Faculty of Udayana University. The number of nursing students on clinical placement at the hospital in 2016 (January-November) and treating patients in the inpatient unit were 667 students, while in the hospital's polyclinic were 167 . On average, there were 6-8 students per ward in the inpatient care on one shift while 3-4 students per day were the average in the polyclinic. This study was conducted in the inpatient care wards of the hospital where students, CIs and nurses have a longer time interactions.

\section{METHODS}

Qualitative study was conducted using in-depth interviews with CIs $(n=4)$ in charge of the inpatient ward, as well as nurses $(\mathrm{n}=8)$, and nursing students $(\mathrm{n}=8)$ in the inpatient ward in June-July, 2017. Participants were selected using purposive sampling based on the participating CI's and nurse's education levels as well as the nursing student's course of study. Nursing students on placement on the ward from June-July, 2017, were chosen; CI participants were also working on the same ward. Nursing-staff participants were selected according to their level of education: 1 nurse with a first degree in Nursing and one with a higher diploma in Nursing.

Interviews were conducted using in-depth interview questions divided into several key themes according to this paper's focus on the clinical mentoring process. The interviews were recorded using a tape recorder and were then transcribed and combined into a single MS Excel document along with the notes the researcher made during interviews.

Data analysis proceeded by coding common themes that emerged from participant's responses so that the key findings could then be compared among the respondent groups. The results are presented narratively in the form of transcript excerpts followed by an analysis of the patterns identified. Informants triangulation technique was used to ensure the internal validity of the data from the three groups. This study has obtained an ethical clearance from the Ethics Committee, Faculty of Medicine, Udayana University/Sanglah General Hospital, Denpasar, Bali on June 15, 2016.

\section{RESULTS AND DISCUSSION}

Three key themes emerged which illustrated the pattern of working relationships between CIs, nurses, and nursing students: (i) perceptions of mentoring; (ii) behaviour during mentoring; and (iii) the patterns of working relationships among CIs, nurses, and nursing students.

\section{Perception of mentoring}

According to CIs, nurses, and nursing students, mentoring is designed to provide educational guidance and assistance to students. However, participants also felt that mentoring was not specifically designed to provide motivation and/or improve student's professionalism. Participant's narrow definition of mentoring is illustrated by the following quote.

"Personally, I am more into the actual method... actually how we deliver something according to the method we use; a mentor should be a role model - an example" (Male clinical instructor, 39)

"Guiding students so that they can practice [medicine] and know the theory - usually, students learn the theory on campus, and now here they are guided in [medical] practice" (Female nurse, degree in Nursing, 28)

Indeed, mentoring is not only designed to provide guidance and assistance; it should also provide encouragement for skills improvement and increase student professionalism. ${ }^{10}$ Analysis of 23 nursing research articles reported that mentoring is useful in facilitating nursing student's learning and strengthening their professionalism. ${ }^{11,12}$ Thus, it appears that CI's, nurse's, and nursing student's narrow perceptions of mentoring as simply guiding and assisting students influences each one's perception of both their own roles and behaviours.

\section{Perceptions of participant roles and behaviour}

The results of the interviews with each group found that they each perceived the role of nursing students in contrasting ways. For instance, nurses described the nursing student's role in terms of easing their own workload by providing nursing care to patients. ${ }^{13-16}$ 
"In terms of the simple tasks like making up bedsand changing IV fluids, then the students help us. But in the case of more complicated tasks, then the students mostly assist us in fetching equipment or instruments" (Female nurse, 30, degree in nursing).

Nurse's perception of nursing student's role as assistants influences their behaviour towards students in the clinical context. For example, nursing students stated that they are often assigned a wide range of tasks to assist nurses in providing care to patients.

"If there are a lot of students, then we only get a little instruction...the work is divided up in a more relaxed way, but if there are only two of us like the other day, then it gets crowded, we don't get to do much" (Female nursing student, 20, studying for a degree in nursing).

Meanwhile, CIs described having nursing students on the ward as a potential burden as they feel pressured to enable students to apply their classroom-based medical knowledge in a practical setting.

"If I see that the student has taken on the task happily, then I'm happy...if not, then I'm not... its ok, we give them tasks to allow them to be able to apply what they learn at university" (Male CI, 40).

In terms of CI's perception of nursing students as an extra workload during the mentoring process, on occasion, CIs expressed that they felt unable to carry out their role as educators due to the many other important duties they are responsible for on the ward.

"Usually, the CI is in charge of the ward...at other times they may not be here as they may be busy in meetings, and that's without factoring in time for supervising [students] so they don't fully focus on us...more often, they help us out if we are unable to cope... then we go to the CIs" (Female nurse, 26, degree in nursing).

Here, the data suggest that CI's multiple roles may negatively impact their performance as mentors to the detriment of student's expectations about the mentoring process. This may explain why both nursing students and CIs sometimes gave negative feedback about clinical mentoring. ${ }^{17}$

However, nurse's perception of students as a potential extra workload depends on student's attitude during their clinical placement. Nursing staff expressed confidence that students were able to reduce this burden depending on their preparedness, attitude, and willingness to participate in the patient care experience. ${ }^{18,19}$

"Sometimes, if students are hardworking and quick on the uptake, they quickly 'get' the task at hand - that makes things easier. But, if there are students who don't pick things up quickly, then it gets a bit more complicated, for example, if we are teaching them [students] at the same time as treating patients, and they need to be told more than once or twice, then this makes things more difficult for us" (Female nurse, 26, degree in Nursing).

Further, a number of nurses claimed that not all students are sufficiently active on the ward, some were described as passive and lacking in initiative, illustrating their lack of commitment to their clinical placement.

"They don't get involved in the clinical work... the passive ones just sit about. At night, they [the passive ones] just sleep through until morning" (Female nurse, 26, degree in nursing).

This finding is supported by several other studies that have revealed medical student's passive attitudes towards clinical placements in hospitals..$^{20,21}$ However, nurse's negative attitudes towards students in terms of providing poor guidance and support can cause students to become frustrated; this can lead to some students under-participating in their placement. ${ }^{19,21}$

Nursing student's view of their own role within the mentoring process tends to focus very much on their position as students on clinical placement. However, in practice, they frequently admitted feeling as though they are treated as extra helpers by the medical staff, and, as such, are often called upon to carry out tasks unrelated to their medical studies.

"Yes, we are here to learn ...we are here to learn what we shouldn't do. But sometimes it feels as though -- sorry but I'm just being honest here -- like we're just an extra pair of hands [for menial jobs], but not all of the nurses are like that, but they [the nurses] do tend to order us around to do this and that, even though we are focused on our [learning] targets" (Female nursing student, 20, studying for a degree in nursing).

The results of the interviews with CIs and nurses also illustrated nursing student's behaviour when 
carrying out practical nursing tasks in patient-care contexts. In general, student behaviour is judged very positively; they interact well and actively perform the tasks required of them in accordance with the aims of the medical placement.

"Whatever [nursing tasks] we carry out, they [students] also carry out - the more active students do as we do. For example, when we are on night duty, the active ones get up at the same time as us" (Female nurse, 30, degree in nursing).

In addition, nurses reported that students were willing to carry out the tasks delegated to them; they often undertook routine nursing-care tasks together with the nurses in accordance with their instructions.

"Usually, tasks are scheduled for specific times for incidental tasks we ask if we can get the students to help out" (Male nurse, 25, higher diploma in nursing).

However, in reality, nursing students on clinical placements should be regarded as students and not as members of the hospital staff even though they make an active contribution to the clinical setting that enables them to learn how to care for patients. ${ }^{22}$ Nursing students often experience conflict between their roles as nursing practitioners (with an attendant responsibility to patient) and their role as students. ${ }^{23}$ This suggests that efforts are needed to re-establish both instructor's and nurse's perceptions of nursing student as students and not fully fledged medical practitioners.

CIs role in the mentoring process is complex; they are seen as mentors, supervisors, and evaluators; a view shared both by CIs and nurses alike.

"I think of myself as a supervisor, as a leader, and an observer. I am also responsible for setting tests for the students" (Male CI, 40)

However, this is at odds with nursing student's assessments of CI's behaviour; nursing students tend to view CIs not as supervisors or leaders but principally as examiners of student's medical knowledge.

"At orientation, we were introduced to the senior nurses, but after that, we were rarely accompanied [on medical tasks]as they were busy with various meetings, except around exam time and when we do nursing-care workshops, as well as revision with the CI" (Female nursing student, 21, studying for a degree in nursing).
These contrasting perceptions, between nursing student's perceptions of CI's roles and responsibilities and CI's own perception's, illustrate that CIs have yet to be seen as successfully fulfilling their roles as facilitators of learning who are able to support nursing students to develop critical thinking skills, improve their medical competence and professional skills, and their attitudes and behaviour on the ward. ${ }^{24,25}$ CI's lack of understanding of their role can negatively impact their performance within the clinical mentoring process.

Similarly, the interviews with the nurses and nursing students cast more light on CI's mentoring performance. They reported that CIs tended to limit their role to evaluating student performance in the clinical context; setting student exams; and responding to student questions. CIs were said to be rarely active in offering guidance and mentoring to students, as revealed by the following quote from a nursing student interviewee.

"I would like to ask the CIs [questions about medical practices] but usually, when we are performing nursing tasks, we are paired up with senior nurses. It's only around exam time that we have any contact with the CIs" (Female nursing student, 20, studying for a degree in nursing).

Another key theme relates to nurse's role in the mentoring process and as role models and leadership for nursing students. In general, CIs and nursing students assessed nurse's role as providing clinical guidance to nursing students, as described in the following excerpt.

"I think nurses play the role of (student) supervisors and also observers, almost as much as the CIs. The only difference is in terms of bedside teaching, exams, and pre-conference training where CIs are directly involved" (Male CI 40).

However, nurses tend to have a different view of CIs and nursing students; nurses view their role in the mentoring process as simply accompanying students in carrying out nursing-care tasks and assume no responsibility for the students in the medical setting. Nurses tend to assume that it is the CI's role to guide and take responsibility for students.

"Actually, we just oversee them [the students] we don't take any responsibility for them; we just shadow them. It's the CI's job to actually guide them on best practice based on nursing theory and take responsibility for them" (Female nurse, 30, degree in nursing). 
Nurses also reported a lack of clarity about their role within the mentoring process; they felt unclear about their responsibilities towards student's medical training. This finding is supported by several other studies that reveal confusion among nursing staff as to their exact function and scope of practice in terms of mentoring student nurses. ${ }^{21,26}$ This uncertainty is likely to have an impact on nurse's behaviour in the clinical learning process; for instance, poorly defined roles can be a source of conflict among the different members of clinical teams and may reduce the effectiveness of patient care and service delivery. ${ }^{27}$

Further, the interviews with CIs and nursing students gave an overview of nurse's behaviour in the mentoring process. For example, nursing-student participants reported that nurses do not always offer supervision when students are providing nursing care for patients; student participants also reported that nurses would assign them tasks beyond the competencies sought by the students and were rarely willing to guide them.

"So far, the nurses have been like "please help me out with this' or 'go and help out that nurse, please' it's like they [the nurses] are just passing us around when really we should really be with the nurse who's actually teaching us" (Female nursing student, 19, studying for a degree in nursing).

The students also reported that while nurses allowed them to carry out nursing tasks and provide care for patients unassisted, they did not take any responsibility for them in the clinical setting. ${ }^{21,28}$ Indeed, this sentiment was echoed by the nurses themselves; they stated that they assumed no responsibility for students on the ward.

"I've never really considered the service standards...because it's actually not my responsibility, I'm not responsible for them...I just monitor" (Female nurse, 30, degree in nursing).

In a related point, nursing staff reported that that do not provide guidance to nursing students for two reasons: first, they have not been trained how to do so; and second, nurses feel that their own role in the mentoring process is unclear. Therefore, they feel unwilling to take any form of responsibility for the nursing students. ${ }^{19,21}$

\section{Working patterns among Cls, nurses, and nursing students in the mentoring process} The current study identified a strictly hierarchical pattern of working relationships among the CIs, nurses, and nursing students interviewed. For instance, the data revealed that nurses did provide guidance and assistance to students when requested to by CIs.

"The head of the ward or the managers let us know where the students are from... like, this one is from STIKES (Bali Medical School) and they ask us to guide them... in terms of what areas the students are studying... they ask us to guide the students in these areas" (Male nurse, 24, higher diploma in nursing).

The nurses have a responsibility to the CIs (who, in this study, are in charge of the ward) to guide and supervise the students; this includes nurses reporting any problems they may face in supervising students to the CIs.

"If a problem comes up [with students], report it to the CI in charge" (Male nurse, 24, higher diploma in nursing).

CI's position in the hospital's organizational hierarchy as the head of the ward is a kin to that of the nurse's direct employer. This chain of command is evident when CIs delegate nurses to offer mentoring and guidance to students on placement. Further, nurses are required to report back to CIs on how well their nursing students are performing. This rigid vertical hierarchy between CIs, nurses, and nursing students operates from top to bottom and vice versa. ${ }^{29}$

A number of studies have suggested that the extent to which CIs and nurses support their nursing students and ward managers is critical to the successful implementation of clinical training. ${ }^{19,21}$ In addition, these studies also found that nursing staff may refuse to collaborate with or train students because they feel that CIs are employed specifically to perform student-monitoring tasks. ${ }^{19}$ In contrast, the present study found that nurses are willing to participate in training and providing assistance to nursing students even though they are not contractually obliged, or even paid, to do so by the University. However, the extent to which the employer-employee relationship between CIs and nurses influences the success of the mentoring process remains unclear.

Another key finding concerning the patterns of working relationships among CIs, nurses, and nursing students revealed that CIs and nurses fail to play a sufficiently effective role as mentors for nursing students. This can be attributed to their lack of understanding that the roles they perform in the mentoring process can impact their behaviour in terms of how well they provide guidance for 
students. For instance, the present study found that CIs rarely guided students and tended to delegate this role to nurses.

"We hardly ever see the CIs... most of them are already assigned [to other tasks]" (Female nursing student, 21, studying for a degree in nursing).

"There are schedules from the campus that set out the official level of guidance CIs should offer by the book...like, in the mornings we should have training sessions with them, but usually, they [CIs] just carry on with their normal work, except if we have a test with them" (Male nurse, 25, higher diploma in nursing).

The nurse's lack of clarity about their role in the mentoring process and their perception that they have little responsibility for the students appears to have a negative impact on their behaviour in the mentoring process. Indeed, the interviews revealed that nurses often failed to assist and guide students in performing nursing care tasks, and further, nurses tended to view student's role as providing an extra pair of hands to ease their own workload.

"The students help us out because we are often very busy-- there are only three of us--although we all join in, but yeah, we get extra help from the students" (Degree-qualified nurse, Cilinaya).

The mentor-mentee relationship occurs within the relationship between teaching and learning, as well as providing leadership and guidance to students, and supporting their professional development. $^{30,31}$ The present study did not specifically set out to identify the relationship between learning/teaching and professional development in terms of the patterns of working relationships among CIs, nurses, and nursing students. However, it did uncover some interesting findings related to learning and professional development in terms of the guidance and assistance provided to students by nurses and CIs. Specifically, the patterns of working relationships among the CIs/nurses and nursing students in this study do not, in fact, reflect a typical mentor-mentee relationship.

Patterns of working-relationships that do not reflect typical mentor-mentee relations will have direct effects on the on-going mentoring process. For instance, the ideal mentoring model promotes interpersonal communication, professional guidance, and professional development, including improving student learning and creating an effective, safe, and comfortable study environment for students. ${ }^{11,31,32}$ However, the present study's results suggest that the student-mentoring process could be greatly improved and that its failings can likely be attributed to the working relationships among CIs, nurses, and student nurses which do not reflect or encourage an effective mentor-mentee relationship.

\section{CONCLUSION}

The patterns of working relationships among the CIs, nurses, and nursing students examined in this paper can be typified as rigidly top-down and hierarchical; they do not reflect typical mentor-mentee working relationships. Also, this situation is further compounded by the working relationships among CIs, nurses, and student nurses, which do not reflect effective mentor-mentee relations. In terms of future research on this topic, investigation on how the efficacy of the mentor-mentee relationship could be enhanced via training would need to be conducted. Further, quantitative research aimed at measuring educational outcomes both pre- and post-mentor training would be valuable.

\section{ACKNOWLEDGEMENT}

The author would like to thank the participants and all parties who have supported the implementation and writing of this study. Special thanks go to Badung District Hospital that has facilitated the process of this study.

\section{REFERENCES}

1. Peraturan Pemerintah Nomor 93 Tahun 2015 tentang Rumah Sakit Pendidikan (Government Regulation No. 93, 2015, on Teaching Hospital). 2015. Available at: http:// kelembagaan. ristekdikti.go.id/wp-content/uploads/2016/ 08/PP_Nomor_93_Tahun_2015.pdf

2. Hariningsih W. Implementasi kinerja perawat di rumah sakit, pendidikan dan komunitas (The implementation of nursing working performance in hospital, education, and community). Bandung: STIK Immanuel Bandung. 2007. Available at: http://igdrsudbuol.blogspot.com/2009/06/ implementasi-kinerja-perawat-di-rumah.html

3. Koohestani HR, Baghcheghi N, Khosravi SH. Frequency, type, and causes of medication errors in student nurses. Iran Journal of Nursing. 2008. 21 (53):17-27

4. Seraji A, Koohestani HR, Baghcheghi N, Rezaei K. Barriers to the reporting of needlestick/sharps injuries among nursing and midwifery students in Arak, Iran. Iranian Journal of Epidemiology. 2011.

5. Khasanah U. Tindakan error prosedur keperawatan: jenis dan faktor penyebabnya pada mahasiswa profesi ners Program Studi Ilmu Keperawatan Fakultas Kedokteran dan Ilmu Kesehatan (Errors in nursing procedure: the types and causes among nursing students at School of Nursing, Faculty of Medicine and Health Sciences). Journal Universitas Airlangga. 2012; 7(2).

6. Omer TY, Suliman WA, Thomas L, et al. Perception of nursing students to two models of preceptorship in clinical training. Nurse Education in Practice. 2013. 13(3): 155-60

7. Lawal J, Weaver S, Bryan V, et al. Factors that influence the clinical learning experience of nursing students at a 
Caribbean school of nursing. Journal of Nursing Education and Practice. 2016; 6(4).

8. Carlson S, Kotze WJ, Rooyen DV. Accompaniment needs of first-year nursing students in the clinical learning environment.Curationis. 2003, 26 (2) : 30-39

9. Mabuda BT, Potgieter E, Alberts U. Student nurses ' experiences during clinical practice in the Limpopo Province. Curationis. 2008; 31(1):19-27.

10. Swihart D. Nurse preceptor program builder. Second edition. 2007.

11. Jokelainen M, Turunen $\mathrm{H}$, Tossavainen $\mathrm{K}$, et al. A systematic review of mentoring nursing students in clinical placements. Journal of Clinical Nursing. 2011;20(19-20):2854-67.

12. Chandan M, Watts C. Mentoring and pre-registration nurse education. 2012; 1-7. Available at: http://www.dphu. org/uploads/ attachements/books/books_5513_0.pdf

13. Msiska G, Smith P, Fawcett T. The 'life world' of Malawian undergraduate student nurses: the challenge of learning in resource-poor clinical setting. International Journal of Africa Nursing Sciences. 2014;1:35-42

14. Waldock J. Facilitating student learning in clinical practice. Nursing New Zealand. 2010; 16(1):14-6.

15. Borrott N, Day GE, Sedgwick M, Levett-Jones T. Nursing students' belongingness and workplace satisfaction: Quantitative findings of a mixed methods study. Nurse Education Today. 2016; 45:29-34.

16. Beskine D. Mentoring students: Establishing effective working relationships. Nursing Standard. 2010; 23(30):35-40.

17. Wilkes $Z$. The student-mentor relationship: a review of the literature. Nursing Standard. 2006; 20(37):42-7.

18. Hathorn D, Machtmes K, Tillman K. The lived experience of nurses working with student nurses in the acute care clinical environment. The Qualitative Report. 2006; 14(2): 227-244.

19. Lapeña-moñux YR, Cibanal-Juan L, Orts-cortés MI, et al. Nurses' experiences working with nursing students in a hospital: A phenomenological enquiry. 2016; 4.

20. Eta VEA, Atanga MBS, Atashili J, et al. Nurses and Challenges faced as clinical educators: A survey of a group of nurses in Cameroon. The Pan African Medical Journal. 2011. 8(28).

21. Emvula O. Perceptions of registered nurses regarding their role in clinical teaching of student nurses at state training hospital in Windhoek, Namibia (Thesis). The University of Namibia. 2016. Available at: http://repository. unam. edu.na/bitstream/handle/11070/1694/Emvula_2016. pdf? sequence $=1$ \&isAllowed $=y$

22. Levett-Jones $T$, Lathlean $J$, McMillan $M$, et al. Belongingness: A montage of nursing students stories of their clinical placement experience. Contemporary Nurse. 2007. 24(2):162-74
23. Mongwe RN. Student nurses' experiences of the field in the Limpopo Province as learning field: A phenomenological study (Thesis). University of South Africa. 2007. Available at: http://uir.unisa.ac.za/bitstream/handle/10500/1512/ thesis.pdf

24. Hayajneh F. Role model clinical instructor as perceived by Jordanian nursing student. Journal of Research in Nursing. 2011; 16(1).

25. Baltimore JJ. The hospital clinical preceptor: Essential preparation for success. Journal of Continuing Education in Nursing. 2004; 35(3):133-40.

26. Gardner G, Chang A, Duffield C. Making nursing work breaking through the role confusion of advanced nursing. Journal of Advance Nursing. 2007. 57(4):382-91

27. Brault I, Kilpatrick K, D’Amour D, et al. Role clarification processes for better integration of nurse practitioners into primary healthcare teams: A multiple-case study. Nursing Research and Practice. 2014.

28. Uukule N. Guidance of student nurses by clinical instructors in a training hospital of Oshana Region (Thesis). The University of Namibia. 2006. Available at: http://repository.unam.na/ bitstream/handle/11070/313/Uukule2006. pdf? sequence $=2 \&$ is Allowed $=y$

29. Hasibuan MSP. Manajemen sumber daya manusia (Management of human resources). 2010. Bumi Aksara. Jakarta.

30. Leshem S. The many faces of mentor-mentee relationships in a pre-service teacher education programme. Creative Education. 2012; 3(4): 413-421.

31. Cho CS, Ramanan RA, Feldman MD. Defining the ideal qualities of mentorship : A qualitative analysis of the characteristics of outstanding mentors. The American Journal of Medicine. 2011; 124(5): 453-458.

32. Okoronkwo IL, Onyia-Pat JL, Agbo ME, et al. Students' perception of effective clinical teaching and teacher behaviour. Open Journal of Nursing. 2013; 3: 63-70.

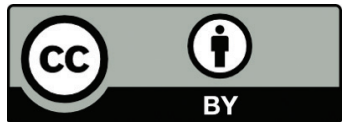

This work is licensed under a Creative Commons Attribution 